\title{
A NEW FEMALE OF ACAMATUS FROM TEXAS
}

\author{
By William S. Creighton \\ Department of Biology, College of the City of New York
}

It has now been almost half a century since Ernest André gave us the first description of one of the peculiar apterous females of the New World legionary ants. Contrary to custom the recognition of this caste added further complexity to an already difficult problem since it showed that the female Eciton as well as the male cannot be correlated with the worker caste by the usual structural criteria. Fortunately the female is not likely to be taken alone but the extreme rarity of this caste and the difficulties attendant upon the capture of some of these insects have greatly impeded our knowledge of the sexual forms of Eciton. The activities of a number of investigators, not infrequently undertaken at considerable personal risk, have resulted in the discovery of females belonging to about a dozen species. There remain, however, almost three times this number of species known only from the worker caste and a large number of described but uncorrelated males. Under such circumstances it is very gratifying to have the privilege of describing another female of these curious insects.

Through the courtesy of Dr. Herbert Ruckes of the Department of Biology of the College of the City of New York, the author was given a colony of Acamatus taken by Dr. Ruckes near Ft. Worth, Texas. This colony contained numerous workers and a single female. I wish to thank Dr. Ruckes for his generosity and to congratulate him upon his good fortune in finding one of these rare insects.

A comparison of the workers from the above colony with material in my collection indicated that they belonged to Emery's species wheeleri. In order to make certain of this determination specimens were sent to Dr. W. M. Wheeler for comparison with type material. Dr. Wheeler, who very 
Psyche, 1932

Vol. 39, Plate 3

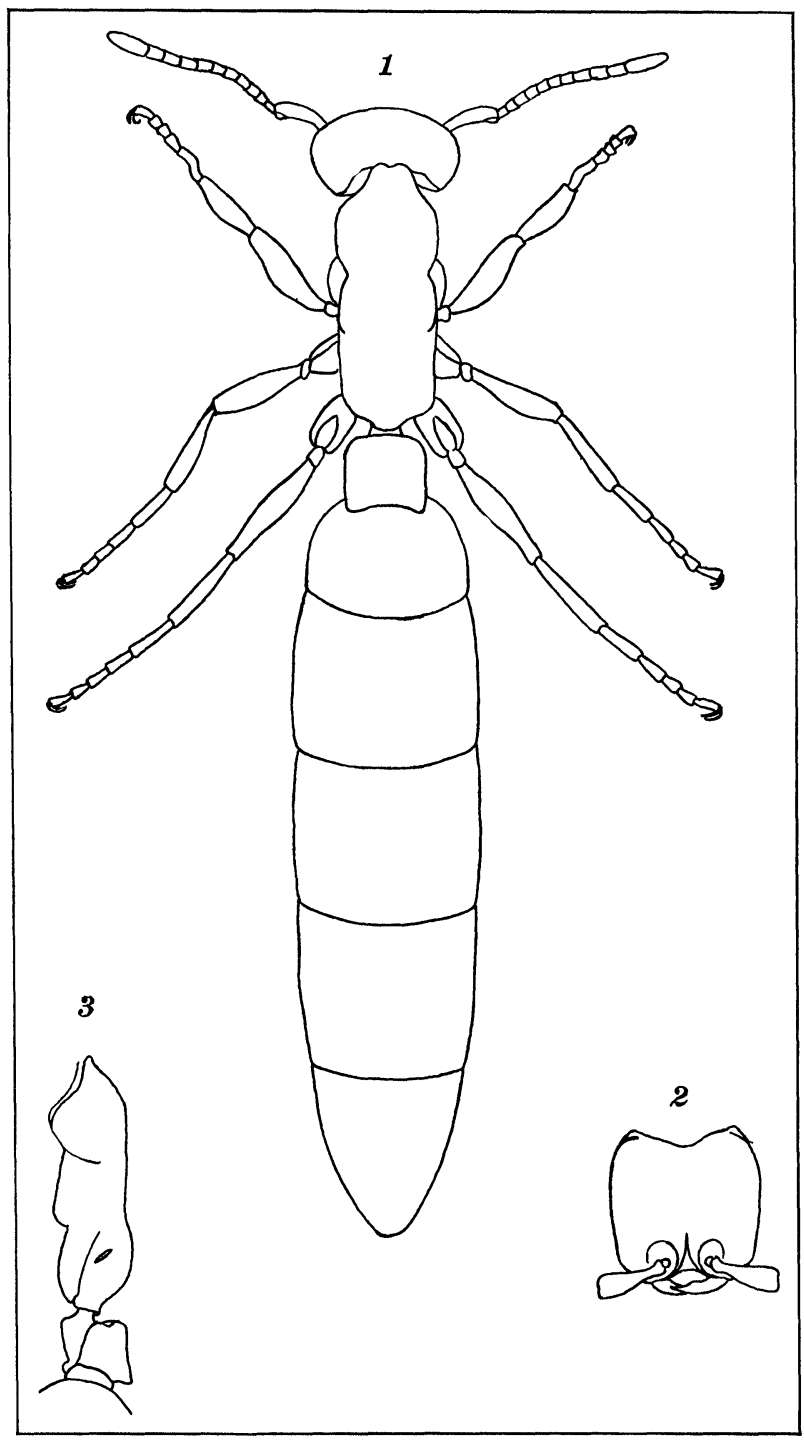

Creighton-Female of Acamatus. 
kindly made the necessary examination, writes me as follows :

"I have compared your specimens of Acamatus with the types of wheeleri Emery in my collection. They differ from these types in having a somewhat shorter head with less produced posterior angles and both the head and promesonotum are distinctly smoother and more shining. In the typical wheeleri the whole thorax is sculptured and subopaque. I believe, therefore, that your form may be regarded as a new subspecies or the hereto unknown worker of one of the Texan species known only from males."

It is much to be regretted that no males were present in the colony since their absence reduces any attempt to correlate this form with a previously described male to pure speculation. It had best, therefore, be regarded as a subspecies of wheeleri until the time when the discovery of a nest containing all the castes will definitely settle the question. In any case the female warrants description since it is markedly different from those of the three North American species of Acamatus in which this caste is known.

Eciton (Acamatus) wheeleri subsp. dubia subsp. nov.

Worker: Head shorter than that of the typical wheeleri, the posterior angles less produced; head and promesonotum smoother and more shining. Otherwise as in the type.

Female: (Plate III, figs. 1, 2 and 3.) Length $13.5 \mathrm{~mm}$. Head, thorax and petiole $4 \mathrm{~mm}$. Gaster $9.5 \mathrm{~mm}$.

Head subquadrate, the sides straight and very slightly convergent in the anterior half, feebly convex in the posterior half. Occiput produced behind into two well-marked lobes each of which passes ventrally to a blunt but distinct angle at the inferior border of the occiput. The middle of the occiput with a prominent, rounded, median groove. Ocelli absent. Eyes consisting of two or three indistinct, unpigmented and depressed facets which lie a little behind the middle of the side of the head. Anterior border of the clypeus evenly concave. Antennal carinæ rather short, the anterior portion partially encircling the antennal fossa, the posterior part fusing with the front a short distance behind the insertion of the antenna. A long, depressed triangular area between the carinæ extends well back behind the pos- 
terior borders of the antennal fossæ (about one-third the length of the head). Mandibles linear with a single acute terminal tooth, the outer border feebly convex, the inner border feebly sinuate. Antennal scapes short, strongly curved and very much enlarged toward the tips. The scape, which is approximately one-half the length of the head, is slightly more than one-third as long as the funiculus. First funicular joint notably smaller than the rest, slightly longer than broad; second joint trapezoidal about as long as broad; the remaining joints all longer than broad, gradually increasing in length apically, the terminal joint bluntly pointed and slightly longer than the two preceding joints taken together.

Thorax two and two-thirds times as long as broad, the dorsum entirely without sutures; pronotum from above subpentagonal, its posterior border marked by a prominent impression in the side of the thorax; mesonotum and epinotum from above forming a single rectangular area having slightly rounded posterior angles and a small, rounded, median projection on the posterior face of the epinotum. Seen from the side the thorax is approximately four times as long as high, the pronotum evenly rounded in front and passing without transition to the flat mesonotum. Epinotum slightly higher than the mesonotum, the basal face moderately convex and passing to the short, abrupt declivious face through a broadly rounded angle. Petiole from above quadrate with the anterior edge perfectly straight, the anterior angles broadly rounded. The anterior portion of the node has a virtually flat upper face but in the posterior half it is broadly and feebly concave. Seen from the side the node of the petiole has a straight upper border which passes to the vertical anterior face through a rounded angle and to the very short posterior face through a much sharper angle. Ventrally the petiole is constricted to form a very thick, short posterior peduncle and a much longer subtriangular portion which extends forward under the node and is narrowed in front to form the anterior peduncle.

Gaster slender, the first segment notably broader than long, segments two, three and four only slightly broader than long, the terminal segment somewhat longer than broad. Hypopygium deeply cleft in the middle, the lobes 
rounded and fringed with abundant hairs; the pygidium bearing two small slender spine-like processes; sting prominent.

Legs rather short, the femora and tibiæ strongly compressed, the tarsal joints of the middle and hind legs all longer than broad. Fore tarsi shorter than the others, the first joint strongly bent, the third and fourth joints as broad as long. Claws well developed.

Smooth and shining throughout. The head with numerous rather coarse, piligerous punctures, those on the thorax somewhat smaller and sparser, abdominal punctures very much smaller and notably sparser. Head covered with short, erect hairs of approximately uniform length. Thoracic hairs sparser and of variable length. Edges of the node of the petiole covered with abundant, long, erect hairs. Hairs on the abdomen long, very slender and appressed, those bordering the edges of the segments somewhat stouter but borne parallel to the surface of the gaster. Apical portion of the middle and hind femora with numerous rather long erect hairs, the remainder of the appendages covered with shorter hairs, these being most abundant on the tarsi and funiculi.

Color, rich reddish brown throughout, the tarsi slightly lighter.

Taken by Dr. Herbert Ruckes about five miles west of Ft. Worth, Texas. Dr. Ruckes notes that the colony, which was a small one, was nesting beneath a large, flat boulder.

The female of wheeleri subsp. dubia can readily be distinguished from those of opacithorax and schmitti in the very different structure of the thorax. The prominent, median epinotal groove which is present in both the latter forms is completely absent in the new subspecies. Moreover in both opacithorax and schmitti the mesoepinotum of the female gradually increases in width from the promesonotal suture rearward. In the female of dubia the sides of the mesoepinotum are parallel except near the anterior end where a slight constriction occurs. In addition the head of the female in opacithorax and schmitti is more narrowed behind and the concavity in the upper face of the node of the petiole is very much deeper and extends entirely across the node to its anterior edge. I have not been able to com- 
pare the female of the new subspecies directly with that of carolinense, but the excellent figure of the female of that species presented in Dr. Wheeler's publication of 1921 permits me to note the following differences: the sides of the head of carolinense are more convex, the occiput only feebly impressed, the epinotum in profile much more angular and no higher than the adjacent portion of the mesonotum.

It seems worth while to note in passing that the figure of the female of Acamatus schmitti given by Emery in the Genera Insectorum is incorrect in regard to the length of the legs. In Emery's figure the hind femora are as long as the greatest width of the thorax with the rest of the appendage proportionally shortened. The impression produced is one of a relatively short-legged insect, whereas, actually the legs of the females of Acamatus bear about the same proportion to the head and thorax as do those of the worker. Measurements of a female of schmitti in my collection show that the hind femora are one and one-quarter times longer than the greatest width of the thorax with the rest of the appendage uniformly longer, especially the tarsal joints which are almost twice as long as those in Emery's figure.

\section{LITERATURE}

Wheeler, W. M. and Long, W. H.

1901. The Males of Some Texas Ecitons. American Natur., Vol. 35, pp. 157-173.

Wheeler, W. M.

1921. Observations on Army Ants in British Guiana. Proc. American Acad. Arts and Sci., Vol. 56, No. 8, pp. 291-328.

Wheeler, W. M.

1925. The Finding of the Queen of the Army Ant, Eciton hamatum Fabricius. Biol. Bull., Vol. 49, No. 3, pp. 139-149. 

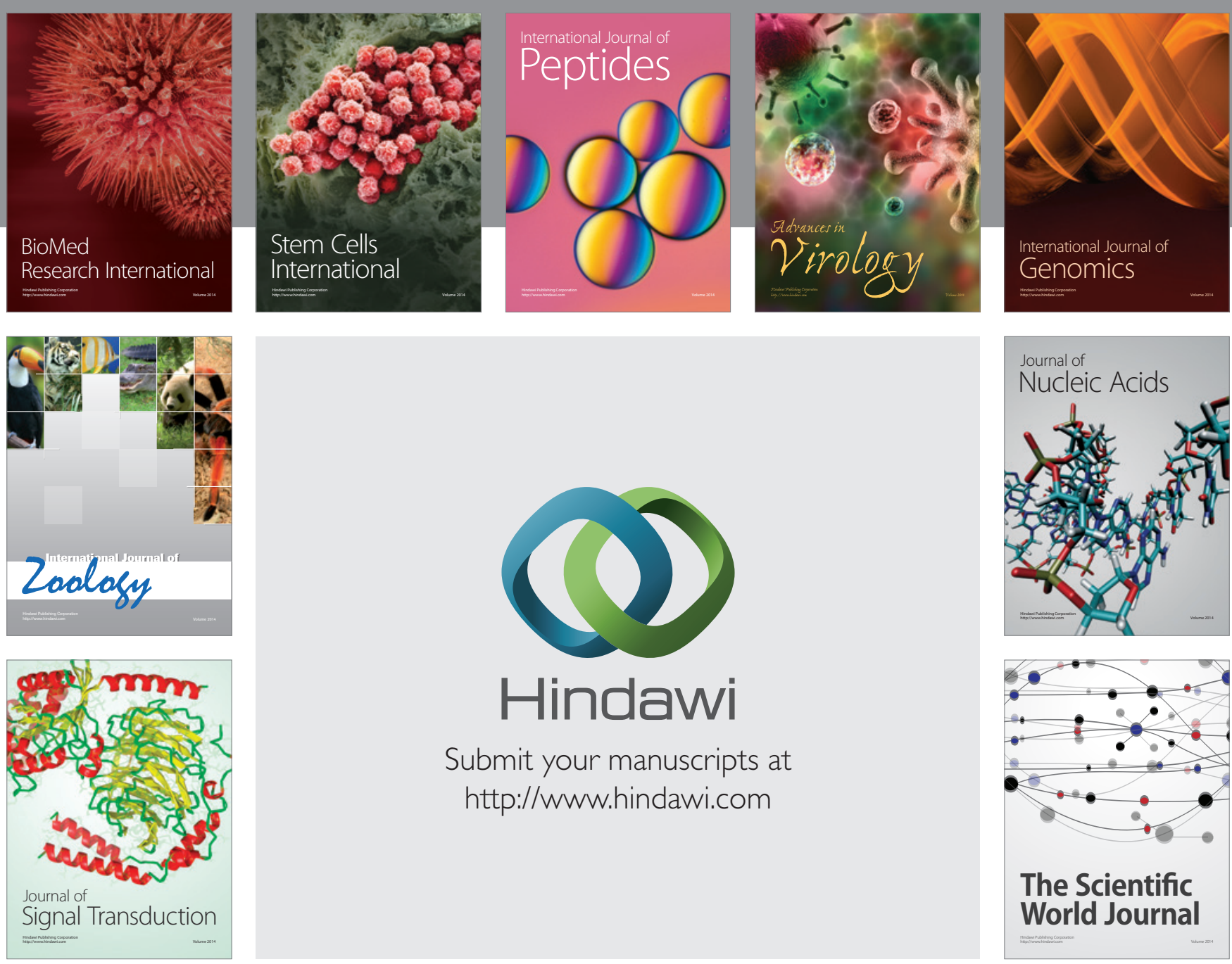

Submit your manuscripts at

http://www.hindawi.com
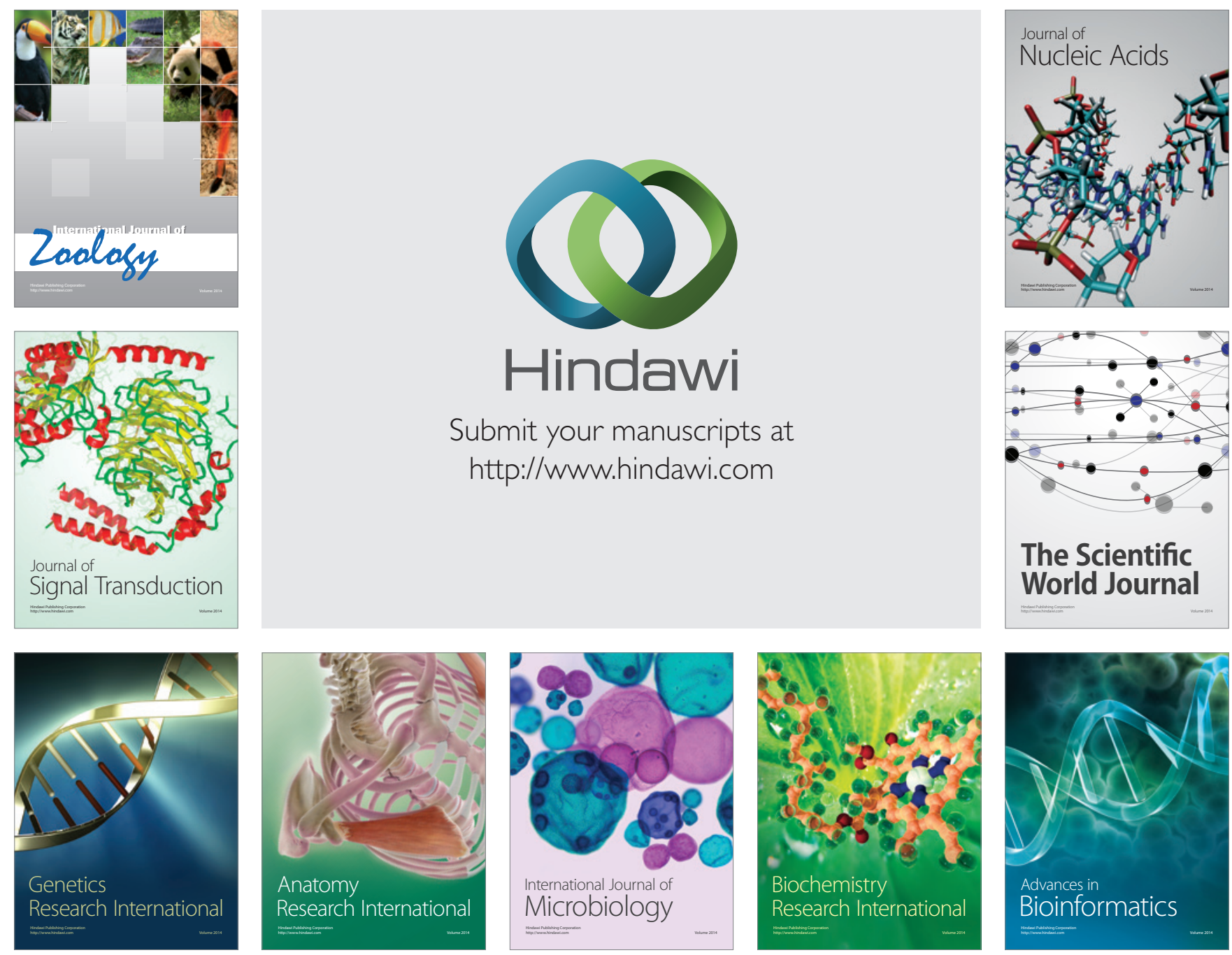

The Scientific World Journal
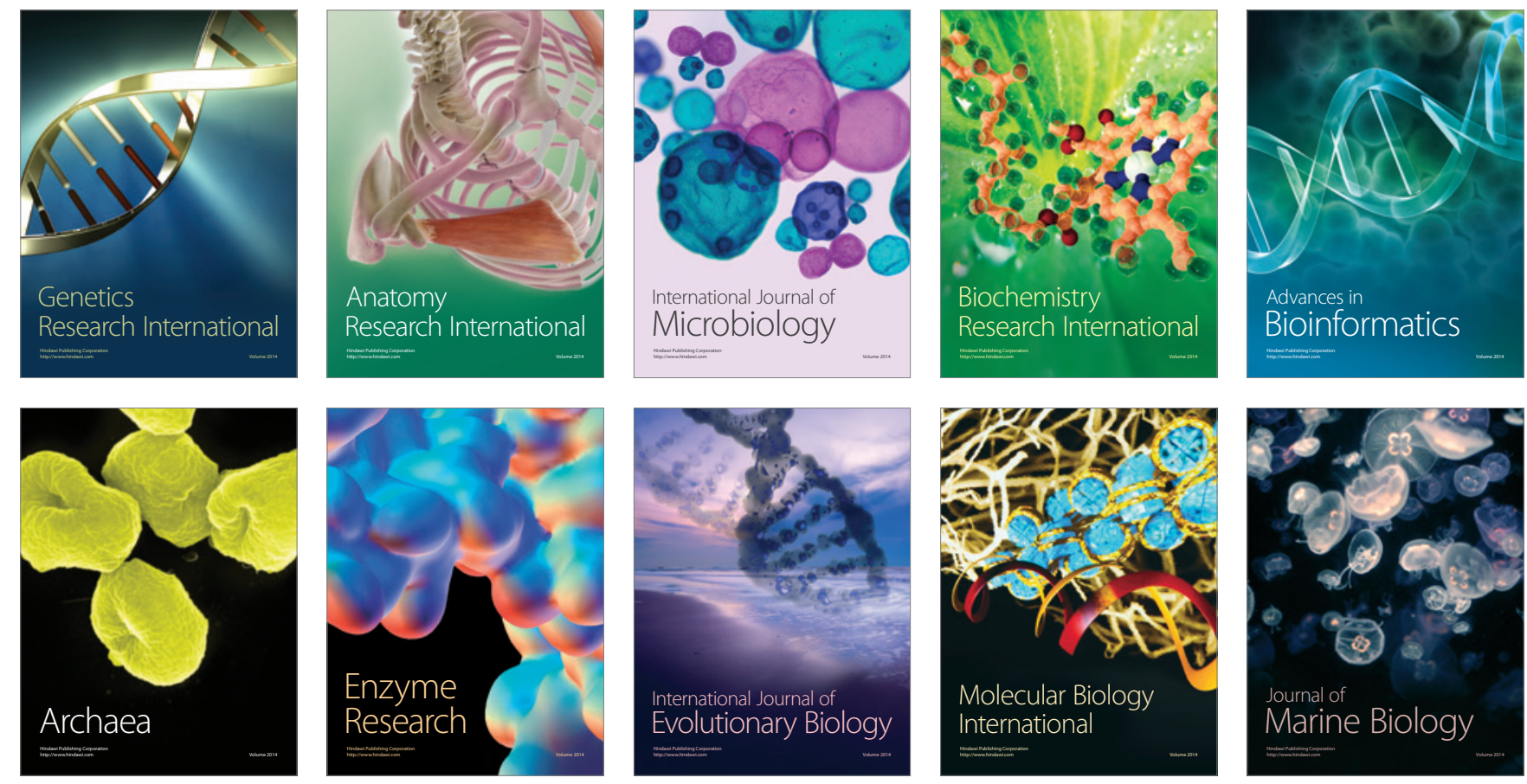